\title{
O Envolvimento Parental na Visáo de Pais e Professores de Alunos COM Necessidades Educacionais EsPeciais ${ }^{1}$ \\ Parental InVOLVEMENT from the PoInt of VIeW of Parents and Teachers of STUDENTS WITH SPECIAL EDUCATIONAL NEEDS
}

\author{
Ana Carolina Camargo CHRISTOVAM ${ }^{2}$ \\ Fabiana CIA $^{3}$
}

\begin{abstract}
RESUMO: em tempos em que a inclusão escolar de crianças com necessidades educacionais especiais vem ocorrendo com maior frequência em idade pré-escolar, produzir dados sobre estes alunos possibilita uma atuaçáo preventiva junto às famílias e às escolas. Além disso, existem evidências científicas de que uma relação parental próxima à escola seja efetiva para a construção de práticas de ensino adequadas a promoçáo do desenvolvimento da criança de modo geral. O objetivo deste estudo foi identificar a percepção dos participantes sobre a relação família-escola, considerando o processo de inclusão. Participaram do estudo 60 pais e 54 professores de crianças NEE, matriculados na pré-escola de uma cidade do interior do estado de São Paulo. Os dados foram coletados por meio de questionários, e analisados utilizando métodos descritivos e análise de conteúdo. Os dados indicam que os fatores importantes ao sucesso do aluno segundo professores seriam o apoio do profissional especializado, e o auxílio aos pais em tudo que envolvesse o desenvolvimento da criança; enquanto pais indicaram a importância de auxiliar alunos e professores na tarefa de casa. Os participantes afirmaram que uma boa relação família-escola seria aquela em que comunicação fosse eficiente. No que diz respeito à promoçấo da relação, professores afirmam a necessidade da escola ser mais atrativa e pais entendem a necessidade desta oferecer orientaçóes sobre como participar. Embora os participantes compreendam a importância de uma relação parental próxima, existem lacunas sobre a melhor forma de realizar esse envolvimento, indicando a necessidade de açóes que promovam o envolvimento parental.
\end{abstract}

PALAVRAS-CHAVE: Educação Especial. Atitudes dos pais. Educação Infantil. Inclusão Escolar.

\begin{abstract}
At a time when inclusion of children with special educational needs has been occurring most frequently at the early childhood education level, producing data on these students enables preventive measures to be taken with families and schools. There is scientific evidence that a close relationship between parents and school is effective for constructing appropriate teaching practices, so as to promote the conditions necessary for child development. The aim of this study was to identify the participants' perceptions about the family-school relationship, considering the inclusion process. The study included 60 parents and 54 teachers of children with special educational needs enrolled in preschool in a city in the state of São Paulo. Data were collected through questionnaires and analyzed using content analysis and descriptive methods. The data indicate that the important factors to student success in the opinion of teachers were the support of expert professionals, and assistance of parents in everything involving the child's development; the parents, in turn, stressed the importance of helping their children and the teachers with homework issues. The participants reported that a good family-school relationship would be one in which communication was efficient. Regarding improvement of the relationship, teachers stated that the school should be made more attractive, while parents suggested that the school needed to offer more guidance on how they could participate more fully. Although the participants understand the importance of a close parental relationship, there are gaps on the best way to accomplish this involvement, indicating the need for programs that promote parental involvement.
\end{abstract}

KEYWORDS: Special Education. Parental Attitudes. Early Childhood Education. School Inclusion.

\footnotetext{
${ }^{1}$ Apoio financeiro: $\mathrm{CNPq}$

${ }^{2}$ Psicóloga, Mestre e Doutoranda em Educação Especial Programa de Pós-Graduação em Educação Especial da Universidade Federal de São Carlos, São Carlos, São Paulo, Brasil. Bolsista CAPES. carolchristovam@hotmail.com

${ }^{3}$ Professora Adjunta do Departamento de Psicologia e do Programa de Pós-Graduação em Educação Especial da Universidade Federal de São Carlos, São Paulo, Brasil. fabianacia@hotmail.com
} 


\section{INTRODUÇÃo}

Embora a ideia da inclusão já esteja presente na Legislação Brasileira, na $1^{\circ}$ Lei de

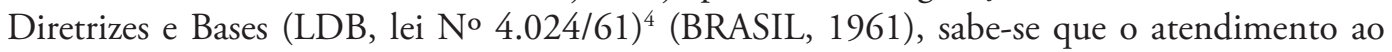
deficiente no contexo educacional brasileiro era realizado seguindo os modelos de internatos ou escolas especiais da Europa, apartando o deficiente de sua sociedade e do direito ao desenvolvimento junto às crianças de sua idade (MAZOTTA, 1996).

Para transpor as barreiras existentes neste contexto e buscando práticas mais inclusivas, os movimentos de integração contribuíram pouco a pouco com a criação de serviços e classes especiais em escolas públicas (MARCHESI, 2004), que passaram a ser garantidas pela legislação brasileira, determinando que as escolas oferecessem serviços de apoio especializados nas escolas comuns, para atender as particularidades da clientela deficiente (BRASIL, 1996). Tais movimentos contribuíram para que práticas preconceituosas e segregacionistas fossem deixadas de lado em direção a uma postura mais inclusiva e igualitária.

Existem muitas indagações sobre os caminhos a serem seguidos nas práticas e implementaçóes de um projeto de educação verdadeiramente inclusivo, sendo que os pressupostos imprescindíveis para o sucesso das políticas inclusivas estão no direito da educação e no exercício da cidadania, uma vez que apenas o acesso à escola não é suficiente para que seja considerada de fato inclusão (MENDES, 2006).

Nos Centros e Escolas de Educação Infantil a orientação para as crianças com Necessidades Educacionais Especiais (NEE) deve partir de programas de intervenção precoce para uma avaliação e identificação da dificuldade, que por meio de um atendimento adequado, pode desenvolver as potencialidades e aprendizagem da criança (BRASIL, 2006).

Para Durlak (1997), a intervenção precoce, ainda na educação infantil, permite a identificação de problemas e a intervenção antes que se tornem severos. Deste modo, produzir dados sobre a inclusão de alunos ainda na educação infantil possibilita uma atuação profilática, preventiva, junto às famílias e as escolas no momento em que as dificuldades da criança começam a emergir ou, antes mesmo que ocorram, de forma a combinar os achados científicos com a atuação prática (VALLE, 2002). Por isso, torna-se essencial que a criança com NEE inicie sua escolarizaçáo o mais cedo possível, contando sempre com o apoio da família, auxiliando amplamente nesse processo, relacionando-se de maneira positiva com a escola, proporcionando condiçóes para um melhor aprendizado e desenvolvimento da criança (POLONIA; DESSEN, 2005).

De um modo geral, pesquisas apontam que os pais têm papéis importantes a desempenhar no desenvolvimento de seus filhos desde a mais tenra idade (BEE, 1996). Ao pensar em teorias que considerem a importância do ambiente, sobretudo o contexto famíliar no desenvolvimento das crianças, vários estudos desenvolvidos nesta perspectiva utilizam o referencial teórico de Bronfrenbrenner (1979) e sua perspectiva bioecológica para explicar o desenvolvimento infantil. Segundo o autor, para que a criança possa se desenvolver nos contextos intelectual, social e emocional é importante que esta participe de forma regular e contínua em atividades recíprocas e progressivamente complexas, sempre com uma ou mais

\footnotetext{
${ }^{4}$ O Título X, Art. $88^{\circ}$ da Lei 4.023/61 versa sobre a Educação de "Excepcionais" e estabelece que "A educação de excepcionais deve, no que for possível, enquadrar-se no sistema geral de educação, a fim de integrá-los na comunidade”.
} 
pessoas que tenham forte ligação afetiva com a criança. Sigolo (2002) ao fazer uso da mesma teoria ressalta que, para Bronfrenbrenner, o desenvolvimento infantil só pode ser entendido ao se considerar integralmente os processos imediatos (físico e social) e distantes (histórico, cultura, social e ambiental), que influenciam o desenvolvimento da criança. A perspectiva de Bronfrenbrenner (1996) reforça a importância do envolvimento do adulto em todos os contextos em que a criança se insere, uma vez que tem consequências importantes no seu desenvolvimento do filho, em todas as áreas.

Quanto às teorias que versam sobre a importância do envolvimento parental nos mais diversos contextos da vida da criança, considera-se importante realizar uma investigação sobre o tema, identificando possíveis contribuiçóes da relação mais próxima entre a escola e a família para o desenvolvimento do aluno e, sobretudo sobre a inclusão com aluno com NEE no ensino comum.

O interesse no envolvimento parental tem origem nas teorias sociológicas que notaram a importância das experiências familiares, tal como a educação dos pais como preditor de bons resultados escolares. A partir desses resultados, pesquisadores começaram a explorar processos em que experiências famíliares poderiam exercer efeitos na educação e no desenvolvimento das crianças, passando a ser entendido como a chave para melhorar os resultados das mesmas (GROLNICK; SLOWIACZEK, 1994).

Existem muitas definiçóes para o termo "envolvimento parental", no entanto, para os fins desta pesquisa, o termo será utilizado para fazer referência à relação estabelecida entre a família e a escola, entendida como uma parceria efetiva com potencial para impactar positivamente na escolaridade de seus filhos. O termo parental será utilizado para se referir a toda e qualquer pessoa do núcleo famíliar do aluno disponível e que participe da vida escolar da criança.

Seguindo a linha de pesquisa internacional sobre envolvimento, vários pesquisadores brasileiros têm reproduzido em suas pesquisas a lógica da pesquisa e política educacional norte americana (EPSTEIN, 1995; SMITH, 1998) e portuguesa (DIAS, 1996; DUARTE, 2001; PEREIRA, 1996; ZENHAS, 2004) sobre as relaçóes família-escola que acreditam que o envolvimento dos pais em casa tem como consequência melhoria do desempenho acadêmico e resulta em melhores práticas educativas, principalmente quando se trata de alunos com NEE (BHERING; DENEZ, 2002; CIA; D’AFFONSECA; BARHAM, 2004; CIA; PAMPLIN; WILLIAMS, 2008; CIA; PAMPLIN, DEL PRETTE, 2006; SOARES; SOUZA; MARINHO, 2004), evidenciando a importância do tema abordado também em nossa realiadade.

Os estudos apresentados ressaltam a importância do envolvimento do adulto para o desenvolvimento da criança, porém, o envolvimento parental é ainda mais importante para o sucesso das crianças com NEE ao serem inseridas em ambientes inclusivos (XU; FILLER, 2008). Ao mesmo tempo em que existem diversos estudos afirmando a importância deste envolvimento, não existe um consenso sobre como o envolvimento se torna uma força positiva no desempenho da criança ou quais fatores atuam para determinar o grau de benefício.

Segundo Pang (2008), envolver os pais na escolaridade dos filhos com deficiência pode ser muito positivo, pois ao conhecer os recursos e as necessidades das famílias, esses 
professores poderão auxiliar os familiares na redução do estresse sofrido e no desafio diário da escolarização, para estabelecer uma interação colaborativa que auxilie no processo de inclusão escolar.

Borges, Gualda e Cia (2011) realizaram estudo com objetivo de verificar a opinião de professores de crianças de educação infantil com NEE sobre a relação família-escola e os comportamentos que poderiam proporcionar uma relação mais próxima entre as duas instâncias. Os resultados evidenciaram que os professores entendem uma boa relação entre família-escola aquela que se dá por meio da troca de informaçóes e diálogo e que a ajuda dos pais seria importante no processo de inclusão. Os professores consideram também que a escola tem políticas para promoção do envolvimento, mas salientam que muitas tentativas de promoção do envolvimento são desnecessárias frente à falta de interesse dos pais.

Tendo em vista a importância da inclusão do aluno deficiente ainda na educação infantil, e as evidências científicas de que uma relação parental mais próxima da escola é efetiva para a construção de práticas de ensino mais adequadas para a promoção das condições necessárias ao desenvolvimento da criança, sobretudo quando se trata de alunos com NEE, salienta-se a importância da continuidade de pesquisas nesta direção, para identificação da percepção de pais e professores sobre as práticas existentes em relação à inclusão do préescolar, identificando também, como se dá o envolvimento desses pais na escolaridade dos filhos. Diante do exposto, o objetivo deste estudo foi identificar como pais e professores de crianças pré-escolares avaliam a relação entre a família e a escola, considerando especificamente o processo de inclusão.

\section{Método}

\subsection{Participantes}

Foram participantes da pesquisa 60 pais e 54 professores de crianças com NEE (deficiência física, deficiência visual, deficiência auditiva, autismo, deficiência intelectual, Síndrome de Down, atraso no desenvolvimento, diagnóstico não concluído, ou crianças que participavam do Atendimento Educacional Especializado), matriculadas na rede municipal de ensino, de uma cidade de médio porte do interior do estado de São Paulo.

Os professores participantes tinham em média 39 anos (variando entre 22 e 64 anos) e média de 13 anos de serviço na docência (com tempo de serviço variando entre um e 25 anos). Suas formaçóes variavam em Pedagogia (55,6\%) e Pedagogia com especializações (44,4\%). Três professoras lecionavam para duas crianças com NEE. Os "pais" ${ }^{5}$ respondentes foram representados por 47 mães, nove pais e quatro avós, com média de idade de 32 anos (variando entre 20 e 54 anos). O grau de escolaridade dos pais participantes variou prioritariamente entre $(21,6 \%)$ Fundamental Completo e (25\%) Fundamental Incompleto.

\subsection{LOCAL DE COLETA DE DADOS}

A coleta de dados junto aos participantes ocorreu em uma sala reservada das Unidades escolares (EU) participantes.

\footnotetext{
${ }^{5}$ Este grupo de participantes composto por pais, mães e avós serão referenciados por "pais" ao longo deste.
} 


\subsection{INSTRUMENTOS}

Para a realização da pesquisa foi utilizado o seguinte instrumento: "Questionário Sobre a Relação Família e Escola no Processo de Inclusão - versão para pais e versão para professores" (Adaptado de DIAS, 1996), cujo objetivo é verificar a opinião dos respondentes quanto à relação entre a escola e a família de crianças com necessidades educacionais especiais. Para a realização desta pesquisa serão consideradas quatro questóes abertas do questionário versão para pais e quatro questóes abertas da versão para professores.

\subsection{Procedimento de Coleta e AnÁlise de dados}

Para identificar os possíveis participantes foi enviado à Secretaria Municipal de Educação um ofício solicitando uma relação das escolas do município que tivessem matriculados na educação infantil ${ }^{6}$ alunos com NEE. Após receber autorização, a pesquisadora contatou os responsáveis pelas UE e apresentou os objetivos da pesquisa e os procedimentos da coleta de dados.

Uma vez obtida à aprovação da direção da escola para realização da pesquisa, pais e professores foram contatados para verificar interesse em participar. Após os pais serem contatados e a coleta agendada, foi realizado contato com o professor da criança em questáo e agendado encontro para realização dos procedimentos. O encontro com os participantes para coleta ocorreu nas UE, e seguiu o seguinte roteiro: apresentação da pesquisa, assinatura do Termo de Consentimento Livre e Esclarecido, explicação e aplicação do questionário.

Quanto à análise de dados, os questionários foram tabulados e analisados por meio de análise de conteúdo e métodos descritivos (COZBY, 2006; SAMPIERI; COLLADO; LUCIO, 2006).

\section{Resultados E discussáo}

A Tabela 1 apresenta a opiniáo dos professores sobre os fatores da escola que podem ter influência no sucesso do aluno com NEE.

Tabela 1 - Opinião dos professores sobre os fatores da escola que influenciam no sucesso do aluno

\begin{tabular}{|c|c|c|}
\hline Categorias & $\%$ & Trechos Ilustrativos \\
\hline $\begin{array}{l}\text { Profissionais especializados assessoran- } \\
\text { do professores. }\end{array}$ & $61,1 \%$ & "Orientação através de especialistas no problema...". \\
\hline Respeito à diversidade. & $38,8 \%$ & $\begin{array}{l}\text { "Todos os alunos devem ser tratados com respeito e carinho } \\
\text { independente de sua condiçâa....". }\end{array}$ \\
\hline Acessibilidade arquitetônica. & $25,9 \%$ & "... adaptação da escola para esses alunos". \\
\hline Adaptação ao material didático. & $24,0 \%$ & $\begin{array}{l}\text { "... as aulas e os materiais utilizados pelos professores para } \\
\text { atender os alunos devem ser preparadas para necessidade da } \\
\text { criança". }\end{array}$ \\
\hline
\end{tabular}

\footnotetext{
${ }^{6}$ Estes alunos podem estar matriculados em Centros Infantis (CI - Creches) como em Escolas de Educação Infantil (EMEI, EMEIEF, CI, e CEIEF).
} 


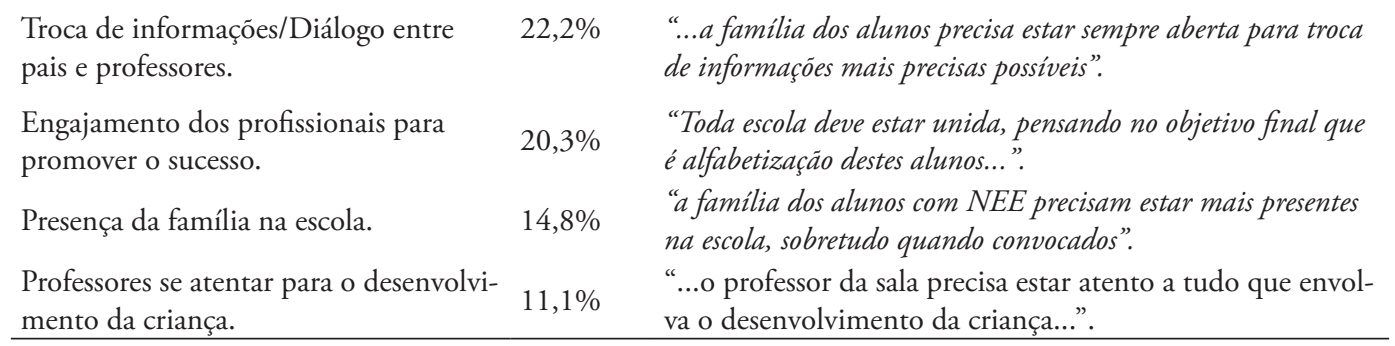

Fonte própria

A maioria dos professores afirmou que o apoio dos profissionais especializados assessorando professores da sala comum pode ser fundamental para o sucesso do aluno com NEE. Esses resultados corroboram os achados de Borges (2012), que ao realizar pesquisa com o mesmo instrumento (DIAS, 1996), também identificou na resposta dos professores o contato com o especialista como fundamental ao sucesso do aluno com NEE.

Segundo os professores inquiridos, o contato com os especialistas seria fundamental para que o professor receba apoio e orientaçáo sobre o problema da criança, podendo intervir de maneira adequada. Esse resultado reafirma a importância do papel do professor especialista, não só no atendimento complementar ao aluno por meio do Atendimento Educacional Especializado (AEE), mas também em seu caráter colaborativo, prestando assessoria aos professores e a comunidade escolar de modo geral, promovendo de fato a inclusáo dos alunos com NEE (CAPELLINI; MENDES, 2007).

Outro fator apontado pelos professores como possível determinante do sucesso escolar do aluno com NEE foi $o$ respeito à diversidade, expressado em forma de preocupação constante em oferecer oportunidades e condiçóes iguais a todos os alunos independentemente de sua condição/dificuldade. Esses dados vêm ao encontro das propostas de educação inclusiva, atualmente em vigor em nosso país, que pode ser caracterizada como uma ação política, cultural, social e pedagógica, em defesa do direito de todos os alunos de estarem juntos, aprendendo e participando, sem nenhum tipo de discriminação, independente de suas condiçóes, promovendo condiçóes de ensino adequadas que favoreça o desenvolvimento de suas capacidades e potencialidades (BRASIL, 2008).

Fatores relacionados à acessibilidade arquitetônica, adequaçôes no ambiente escolar e a adaptação do material didático também foram apontados como importantes para o sucesso do aluno com NEE. Por meio da fala dos professores foi possível identificar não só a adaptação do ambiente, mas a organização do espaço físico, para promover o desenvolvimento e a inclusão dos alunos deficientes são imprescindíveis para o sucesso do aluno. Corroborando com as determinaçóes da LDB (BRASIL, 1996) que asseguram o acesso arquitetônico e a adaptação dos materiais.

A troca de informaçôes entre a família e a escola também foi apontada pelos professores como fator de influência no sucesso da criança. A troca de informaçóes entre as duas instâncias é normalmente apontada na literatura como uma das mais importantes formas de realizaçáo do envolvimento parental na escola, podendo ser fundamental para o desenvolvimento do aluno 
com NEE. Para Bhering e Siraj-Blatchford (1999) a comunicação entre a família e escola deve ser entendida como importante instrumento que efetiva a relação escola-família, agindo como um facilitador e promotor desta relação, podendo ter influências positivas no desenvolvimento da criança, corroborando com o apontado pelos professores.

A Tabela 2 apresenta a opinião dos pais sobre como sua colaboração pode influenciar o sucesso do filho.

Tabela 2 - Opinião dos pais sobre como sua colaboração pode influenciar no sucesso do filho

\begin{tabular}{|c|c|c|}
\hline Categorias & $\%$ & Trechos Ilustrativos \\
\hline Auxiliando nas liçóes de casa. & $23,3 \%$ & $\begin{array}{l}\text { "Acho que ajudar na tarefa de casa é uma forma de } \\
\text { ajudar meu filho a ser bem sucedido na escola". }\end{array}$ \\
\hline $\begin{array}{l}\text { Apoaindo a criança, incentivando a inde- } \\
\text { pendência e autonomia. }\end{array}$ & $21,6 \%$ & $\begin{array}{l}\text { "Se eu incentivar meu filho a participar das coisas, ele fi- } \\
\text { cará seguro e aproveitará melhor o que ocorre na escola". }\end{array}$ \\
\hline $\begin{array}{l}\text { Informando a escola sobre o desenvolvi- } \\
\text { mento da criança. }\end{array}$ & $20,0 \%$ & $\begin{array}{l}\text { "Acho que para meu filho ser bem sucedido devo } \\
\text { partilhar toda e qualquer informação sobre o desen- } \\
\text { volvimento" }\end{array}$ \\
\hline $\begin{array}{l}\text { Tudo pode influenciar o desempenho do } \\
\text { meu filho. }\end{array}$ & $20,0 \%$ & $\begin{array}{l}\text { "Tudo que eu fizer em relação à escola pode influenciar o } \\
\text { sucesso do meu filho". }\end{array}$ \\
\hline Valorizando o trabalho da escola. & $20,0 \%$ & $\begin{array}{l}\text { "Valorizar o trabalho da escola faz com que meu filho } \\
\text { entenda a importância do trabalho realizado lá...". }\end{array}$ \\
\hline Continuando o aprendizado em casa. & $15,0 \%$ & "Dar continuidade do aprendizado da escola". \\
\hline $\begin{array}{l}\text { Gostaria de saber mais como posso } \\
\text { influenciar a aprendizagem. }\end{array}$ & $15,0 \%$ & $\begin{array}{l}\text { "Não sei como posso influenciar o resultado do meu filho, } \\
\text { mas gostaria de saber...". }\end{array}$ \\
\hline $\begin{array}{l}\text { Estar atento para detectar os problemas } \\
\text { de desenvolvimento/ aprendizagem do } \\
\text { aluno }\end{array}$ & $13,3 \%$ & $\begin{array}{l}\text { "... Eu preciso ficar atento a tudo que ocorra com meu } \\
\text { filho para que possa identificar algo errado e poder agir } \\
\text { no tempo certo". }\end{array}$ \\
\hline Tendo uma relação de respeito mútuo. & $10,0 \%$ & $\begin{array}{l}\text { "Acho que se eu respeitar à escola, meu filho também } \\
\text { irá,aumentando suas chances de sucesso". }\end{array}$ \\
\hline Levando o filho a outros profissionais & $3,3 \%$ & $\begin{array}{l}\text { "Acho que levar meu filho aos médicos solicitados pela } \\
\text { equipe escolar pode ser importante para o seu sucesso...". }\end{array}$ \\
\hline Dando uma boa educação familiar & $5,0 \%$ & "Educando, explicando o que é certo e o que é errado". \\
\hline $\begin{array}{l}\text { Participando das reuniôes de pais com } \\
\text { frequência. }\end{array}$ & $3,3 \%$ & $\begin{array}{l}\text { "Estar nas reuniôes de pais pode influenciar no } \\
\text { sucesso dele...". }\end{array}$ \\
\hline
\end{tabular}

Fonte própria

No que diz respeito à opinião dos pais sobre como sua colaboração com a escola pode ser importante ao sucesso de seu filho, é possível identificar uma grande diversidade de respostas, indicando possívelmente a pouca clareza dos pais sobre como seu auxílio pode ter influências no desempenho da criança.

Os pais afirmam entender que auxiliar aluno na realização da tarefa de casa pode ser uma forma de colaboração importante à escola. Segundo estudo de Almeida e Christovam (2008) quanto melhores às condiçóes dispostas pelos pais no ambiente doméstico de alunos em idade pré-escolar, melhor será o desempenho dessas crianças na tarefa de casa, e também 
a concepção do professor sobre a família, melhorando as chances de uma comunicação mais eficiente entre as duas partes, e melhora no desempenho da criança.

Os pais também responderam que sua ajuda pode ser importante Apoiando a criança, incentivando a independência, autonomia e socialização. Esses dados corroboram com Brazelton e Greenspan (2002) que afirmam que a família pode ser caracterizada como um excelente ambiente de desenvolvimento ao atender as necessidades da criança. Assim, ao apoiar a criança e suprir suas necessidades, a família estaria proporcionando melhora no desempenho da criança.

Respostas como Tudo pode influenciar o desempenho do meu filho e Valorizando a escola, mostram o reconhecimento dos pais, que sua atitude em relação à escola pode ser decisiva sobre o desempenho da criança na escola. No entanto, nota-se que podem ser falas genéricas dos pais, ou seja, que eles não têm uma precisão de quais comportamentos parentais podem ser importantes para o desempenho acadêmico e desenvolvimento do filho. Segundo Ferreira e Triches (2009), a principal forma de sensibilização dos pais sobre a importância do envolvimento parental é justamente entender o valor social de seu papel na educação dos filhos. Com isso, os pais podem compreender sua função no processo de desenvolvimento, acarretando também numa diminução do estresse decorrente de questóes comuns do ínicio da escolarização infantil atuando de maneira positiva e aumentando as chances de sucesso da criança.

Quando perguntados sobre como entendem que sua ajuda pode ser válida, 15\% pais apresentaram como resposta que gostariam de obter mais informaçôes sobre como atuar de maneira positiva para ajudar a escola, sugerindo a importância de um programa de promoção do envolvimento parental. Esse interesse dos pais em conhecer mais sobre como promover a relação com a escola, corroboram com a pesquisa de Pamplin (2005), que concluiu que embora muitas vezes a Educação Especial do município considere positiva a participação dos pais na escolaridade, ela não dispóe de mecanismos para promoção do envolvimento, sugerindo a necessidade da implementação de programas de envolvimento.

A Tabela 3 apresenta a opiniáo dos professores sobre como deveria ser uma boa relação entre a família e a escola.

Tabela 3 - Opinião dos professores sobre como deveria ser a boa relação entre família e a escola

\begin{tabular}{|c|c|c|}
\hline Categorias & $\%$ & Trechos Ilustrativos \\
\hline Boa comunicação pais- professores & $64,8 \%$ & $\begin{array}{l}\text { "...um bom diálogo é fundamental para que se possa decidir } \\
\text { junto o melhor para o aluno com NEE." }\end{array}$ \\
\hline Maior participação dos pais & $44,4 \%$ & $\begin{array}{l}\text { "...parte de uma boa relação se refere a participação dos pais, } \\
\text { tanto nas atividades como nas reunióes." }\end{array}$ \\
\hline Relação de parceria & $40,7 \%$ & $\begin{array}{l}\text { "...uma boa relação é aquela em que pais e professores traba- } \\
\text { lham como parceiros, cada um cooperando onde pode, sempre } \\
\text { visualizando um bem maior que é o avanço da criança". }\end{array}$ \\
\hline Valorizando o trabalho da Escola & $11,1 \%$ & $\begin{array}{l}\text { "... entendo que muito do que as crianças fazem aprendem } \\
\text { vendo os pais fazerem, assim, acho que é fundamental que os } \\
\text { filhos vejam os pais valorizando o trabalho da escola, para que } \\
\text { a relação funcione de maneira adequada". }\end{array}$ \\
\hline
\end{tabular}


Contribuiçáo da escola na indepen-

dência e socialização da criança

Contar sobre os comportamentos

dos filhos em casa para o professor

A relação família escola pode não

favorecer a inclusão
“... acho que uma boa relação é aquela que os pais apoiam a escola e juntos contribuem para independência e desenvolvimento da criança, acho que isso torna as crianças mais seguras".

"... é aquela relação em que os pais nos procuram para falar tudo que envolva a criança e, principalmente, aspectos relacionados ao comportamento da criança em casa...".

"No meu caso, eu acho que nem sempre os pais sáo bem $1,8 \%$ vindos, porque se eles não sabem como ajudar, podem acabar atrapalhando o processo de inclusão do filho deficiente".

Fonte própria

Os dados apresentados na Tabela 3, sobre a opiniáo dos professores de como se estabeleceria uma boa relação família-escola indica que: a Comunicação, Uma maior participação dos pais e Uma relação de parceria seriam os principais fatores para se estabelecer uma boa relação entre as duas instâncias. A Tabela 4 apresenta a opiniāo dos pais sobre como deveria ser uma boa relação entre a família e a escola.

Tabela 4 - Opinião dos professores sobre como deveria ser a boa relação entre família e a escola

\begin{tabular}{|c|c|c|}
\hline Categorias & $\%$ & Trechos Ilustrativos \\
\hline $\begin{array}{l}\text { Boa comunicação e compreensão entre } \\
\text { pais e professores. }\end{array}$ & $56,6 \%$ & $\begin{array}{l}\text { "Um bom diálogo é fundamental para que a relação seja } \\
\text { boa...". }\end{array}$ \\
\hline Uma relação de parceria. & $45,0 \%$ & $\begin{array}{l}\text { "Acho que pais e professores precisam ser unidos, como } \\
\text { uma equipe, cada um fazendo sua parte para que inclusão } \\
\text { ocorra". }\end{array}$ \\
\hline Maior participação dos pais na escola. & $23,3 \%$ & $\begin{array}{l}\text { "Acho que uma boa relaçao é aquela que os pais partici- } \\
\text { pam mais ativamente da escola...". }\end{array}$ \\
\hline $\begin{array}{l}\text { Receber informaçóes da escola sobre os } \\
\text { procedimentos trabalhados. }\end{array}$ & $8,3 \%$ & $\begin{array}{l}\text { “... uma boa relaçấo é aquela que a escola deixa os pais } \\
\text { a par de tudo que faz e dos métodos utilizados com as } \\
\text { crianças...". }\end{array}$ \\
\hline $\begin{array}{l}\text { Receber informações sobre o desempe- } \\
\text { nho da criança sucessos/insucessos. }\end{array}$ & $6,6 \%$ & $\begin{array}{l}\text { “... além de informar sobre os métodos, os professores } \\
\text { precisam compartilhar os pontos que a criança está avan- } \\
\text { çando e os que estâo com dificuldade ainda...”. }\end{array}$ \\
\hline $\begin{array}{l}\text { Relação em que os pais ajudam a crian- } \\
\text { ça a ir bem na escola }\end{array}$ & $11,6 \%$ & $\begin{array}{l}\text { "... acho que a relação é boa quando a criança vai bem na } \\
\text { escola...". }\end{array}$ \\
\hline Não soube informar. & $15,0 \%$ & “... não sei dizer...”. \\
\hline
\end{tabular}

Fonte própria

Em relação à opinião dos pais sobre como se estabeleceria uma boa relação famíliaescola, é possível verificar que, assim como os professores, estes consideram a comunicação, uma relação de parceria e a maior participação dos pais, os principais fatores para se estabelecer de uma boa relação.

Os dados apresentados nas Tabelas 3 e 4 indicam que, tanto professores como pais, consideram a comunicação como uma das características mais importantes de uma boa relação família-escola. A comunicação pode ser entendida como a base de qualquer relação entre a 
família-escola, pois é o que permite tudo o que pode ser criado e desenvolvido entre os pais e a escola (BHERING; SIRAJ-BLATCHFORD, 1999).

Uma maior participação dos pais na escola também foi apontado por professores e pais e como indicativo de uma boa relação entre a família e a escola. Por meio das respostas dos participantes foi possível identificar, que segundo estes, é necessário que os pais apresentem mais interesse em participar da escolaridade dos filhos, pois muito pouco é feito, e o que se efetiva não resulta em melhorias no desempenho escolar das crianças.

Conforme Paniagua e Palácios (2007), muitas vezes, a escola diz que a família não participa da vida escolar dos filhos, mas ao verificar esta participaçáo, identificava-se que a participação da família ocorria, porém não atendia as espectativas da escola. Muitas vezes, o que ocorre é que a escola espera que a família aja de uma determinada maneira, e esta maneira pode não ser a vivenciada pela família. Isso aponta para o fato de que para que uma maior participação dos pais ocorra seja necessário que ambas instâncias se comuniquem de maneira adequada, ouvindo um ao outro, e entendendo a contribuição possível.

Vilas Boas (2001) afirma que além dos pais quererem participar da vida escolar dos filhos, é necessário que os professores permitam o envolvimento parental porque, caso não o façam, estariam limitando o envolvimento dos pais. Neste sentido, a autora sugere alguns passos para operacionalizar essa permissão necessária por parte dos professores e contaria com: (a) compreender que a eficácia dos pais relativamente ao seu envolvimento individual no processo de ensino e aprendizagem depende de iniciativa e do convite dos professores; (b) confirmar este envolvimento, lembrando aos pais os seus direitos e deveres; (c) facilitar este envolvimento, proporcionando aos pais as informaçóes que necessitem de conhecer; (d) encorajar a colaboração, desenvolvendo atividades interativas; (e) reconhecer os resultados da participação, favorecendo uma informação adequada do desempenho dos alunos.

É importante notar também, que segundo a Tabela 4, 15\% dos pais apontaram não saber informar o que seria uma boa relação família-escola. Este resultado indica que provavelmente o tipo de concepção que os pais têm sobre a relação família-escola é muito restrito, limitando sua ação dentro da escola. Aponta-se a necessidade de mudar a concepção destes pais para que possam participar ativamente da escolaridade, favorecendo processo de aprendizagem da criança.

A Tabela 5 apresenta a opiniāo dos professores sobre as situaçóes que julga que sua ajuda seria importante aos pais.

Tabela 5 - Opinião dos professores sobre as situaçóes que a sua ajuda seria importante para os pais

\begin{tabular}{lcl}
\hline Categorias & $\%$ & Trechos Ilustrativos \\
\hline $\begin{array}{l}\text { Em tudo que envolva o desenvolvi- } \\
\text { mento da criança. }\end{array}$ & $\begin{array}{l}\text { "Precisamos mostrar aos pais que eles devem estar atentos a todo } \\
\text { e qualquer tipo de alteração no desenvolvimento da criança, já } \\
\text { que isto pode ser indicativo de algo que náo funcione de acordo } \\
\text { com o esperado... }\end{array}$
\end{tabular}


Melhorar a comunicação entre pais e professores.

Orientar os pais sobre como realizar o envolvimento.

Incentivar o aprendizado.

$16,6 \%$

Passar orientações de outros técnicos aos pais.

Não sabe como sua ajuda pode ser útil aos pais.

Diagnóstico precoce e orientaçóes para encaminhamento.

Conversar sobre o comportamento do filho e dos colegas.

Fonte própria
“... não só os pais devem nos informar do que acontece em casa, mas nossa comunicação com eles também precisa ser amplia$d a$, para eles tenham uma dimensão mais adequada do que é esperado para aquela determinada faixa etária...".

“...sinto que muitas vezes os pais não sabem como podem ser úteis, e talvez, uma de nossas funçôes seja justamente orientálos a ser parceiros da escola...".

"Acho que enquanto professores, temos que ensinar os pais a incentivar o aprendizado das crianças, já que essas aprendem muito com as atitudes do pai... Se a criança perceber o pai incentivando a aprendizagem, irá perceber a importância disso para seu desenvolvimento".

"Podemos ser multiplicadores das informaçóes transmitidas por outros profissionais, ensinando, por exemplo, os pais a estimularem seus filhos em casa...".

"Acho que seria muito importante, que nós professores fossemos capacitados, para poder ensinar de fato aos pais, as formas mais adequadas de participar da escolaridade dessas crianças".

"Quanto mais atentos os pais estiverem ao desenvolvimento da criança, maiores são as chances do professor poder ajudá-lo a realizar encaminhamentos a serviços adequados, de modo a identificar o mais urgente possivel o diagnóstico desse aluno".

"Informaçóes sobre o comportamento e desenvolvimento/ aprendizagem da criança na escola."

Os dados da Tabela 5 indicam que os professores consideram que sua ajuda seria importante aos pais: Em tudo que envolva o desenvolvimento da criança, Melhorando a comunicação, Orientando os pais a realizar o envolvimento parental e Incentivando o aprendizado. A Tabela 6 apresenta a opiniāo dos pais sobre as situaçóes que julga que sua ajuda seria importante aos professores.

Tabela 6 - Opinião dos pais sobre as situaçóes que a sua ajuda seria importante para o professor

\begin{tabular}{|c|c|c|}
\hline Categorias & $\%$ & Trechos Ilustrativos \\
\hline Ajudar na tarefa de casa. & $41,6 \%$ & $\begin{array}{l}\text { "... ajudar men filho a realizar a tarefa que a professora envia } \\
\text { para casa...". }\end{array}$ \\
\hline $\begin{array}{l}\text { Em tudo que envolva o desenvolvi- } \\
\text { mento da criança. }\end{array}$ & $35,0 \%$ & $\begin{array}{l}\text { "... acho que estar atento ao desenvolvimento do meu filho e comu- } \\
\text { nicar ao professor pode ser importante ....". }\end{array}$ \\
\hline Incentivar o aprendizado. & $18,3 \%$ & $\begin{array}{l}\text { "...acho que eu posso ser útil incentivando o aprendizado e } \\
\text { tudo que diga respeito a escola...". }\end{array}$ \\
\hline $\begin{array}{l}\text { Gostaria de saber de que forma } \\
\text { minha ajuda pode ser importante ao } \\
\text { professor. }\end{array}$ & $15,0 \%$ & “... não sei como ajudar o professor, mas gostaria de saber...”. \\
\hline $\begin{array}{l}\text { Maior comunicação entre pais e } \\
\text { professores. }\end{array}$ & $11,6 \%$ & $\begin{array}{l}\text { "... conversando frequentemente com o professor sobre tudo que } \\
\text { envolva meu filho....". }\end{array}$ \\
\hline Valorizar a escola. & $10,0 \%$ & $\begin{array}{l}\text { "Acho que se eu valorizar a escola, meu filho entederá o valor dela, } \\
\text { e isso pode facilitar o trabalho do professor". }\end{array}$ \\
\hline
\end{tabular}


Passar orientações médicas aos professores.

Conversar sobre o comportamento do filho e dos colegas.

Prestar serviços voluntários a escola.
$6,6 \%$

$3,3 \%$

$1,6 \%$
“... comunicar o professor de informaçôes obtidas pelos técnicos na APAE..."

“... conversar com o professor sobre o comportamento do meu filho em casa e na escola...".

“... acho que prestar serviços voluntários à escola pode ajudar o professor...”.

Fonte própria

Em relação à opinião dos pais sobre como sua ajuda seria importante ao professor estes consideram: o auxílio à tarefa de casa, em tudo que envolva o desenvolvimento da criança e incentivando o aprendizado, estes dois itens corroboram com a resposta dos professores na Tabela 6. Os pais também apresentaram como resposta, que gostariam de saber como sua ajuda pode ser importante ao professor.

Os dados apresentados nas Tabelas 5 e 6 indicam que as informaçóes sobre tudo que envolva o desenvolvimento da criança são importantes, tanto a pais quanto a professores. Estas informações são importantes para as duas instâncias, pois elas poderão delinear o tipo do trabalho a ser realizado tanto em casa, como na escola. Esse dado corrobora com a afirmação de Xu e Filller (2008), que afirmam que a comunicação entre pais e professores deve ser implementada, priorizando informaçóes sobre a criança nos dois contextos, de modo a proporcionar intervençóes que levem em consideração o que ocorre nos dois ambientes, conduzindo atividades com maiores chances de alcançar o resultado esperado.

Pais e professores também concordam ao responder, que seria importante um ajudar o outro no que diz respeito ao incentivo a aprendizagem. Segundo Ferreira e Triches (2009), a valorização da escola e da aprendizagem seria a melhor maneira dos envolvidos na relação família-escola entenderem seu papel na educação dos filhos e desenvolverem em conjunto um trabalho positivo em relação à escolarização da criança.

Os professores apontaram também que sua ajuda poderia ser importante para melhorar a comunicaçáo com os pais. Campos, Füllgraf e Winggers (2006) realizaram um levantamento bibliográfico, por meio da coleta de produçóes sobre a educação infantil no Brasil, e identificaram existir bloqueios na comunicação entre as famílias, tanto nas creches, quanto nas pré-escolas, que na maioria das vezes, era percebida pelas equipes escolares de forma negativa e preconceituosa. Cabe ao professor, enquanto participante desta relação, romper estas barreiras e auxiliar a família a realizar uma comunicação mais eficiente.

Os professores também relataram entender que sua ajuda pode ser importante aos pais oferecendo informaçóes sobre como realizar o envolvimento e corroboram com o relato dos pais ao responderem que gostariam mais de saber como podem ser úteis. Ao assumir o seu papel no processo de envolvimento parental, os professores podem estabelecer condiçóes adequadas para um envolvimento adequado e efetivo, trazendo benefícios a todos os envolvidos. Para Ferreira e Triches (2009), uma participação ativa dos pais na escola depende que os professores encontrem nas relaçóes um equilíbrio, diversificando estratégias de participação dos pais, intencionalizando e mobilizando os pais para discutirem o assunto e para que possam assumir seus papéis nesta parceria. 
Já, o desejo dos pais, em saber como podem ser úteis aos professores, volta a dizer da importância do preparo da escola ao lidar com os pais e promover o envolvimento adequado dos mesmos. Segundo Pereira (1996), o sucesso do trabalho com as crianças com NEE e suas famílias dependerá em parte, do grau de preparo dos profissionais envolvidos no trabalho. A autora apresenta como características importantes do profissional: capacidade em dar apoio emocional, fornecer informação adequada, garantir ajuda de outros pais e implementar programas adequados.

A Tabela 7 apresenta a opiniāo dos professores sobre o que a escola poderia fazer para aproximar os pais da escola.

Tabela 7 - Opiniáo dos professores sobre o que a escola deveria fazer para aproximar os pais da escola

\begin{tabular}{|c|c|c|}
\hline Categorias & $\%$ & Trechos Ilustrativos \\
\hline $\begin{array}{l}\text { Escola ser mais atrativa aos pais/açóes } \\
\text { que tragam os pais. }\end{array}$ & $46,3 \%$ & $\begin{array}{l}\text { "... eu vejo muitas vezes que os pais de alunos com NEE } \\
\text { säo chamados apenas pra saberem dos insucessos do filho... } \\
\text { Acho que esta estratégia tem que mudar para que a escola } \\
\text { seja mais atrativa aos pais, despertando o interesse pelo que } \\
\text { ocorre na escola...". }\end{array}$ \\
\hline $\begin{array}{l}\text { Orientar sobre como realizar o envol- } \\
\text { vimento. }\end{array}$ & $38,8 \%$ & $\begin{array}{l}\text { “... percebo que muitos pais estão a fim de ajudar, } \\
\text { mas não sabem como serão úteis, então, acho que é } \\
\text { importante que a escola oriente a melhor maneira de se } \\
\text { envolver para ter consequências positivas no desenvolvi- } \\
\text { mento da criança...”. }\end{array}$ \\
\hline $\begin{array}{l}\text { A escola já faz a parte dela, porém os } \\
\text { pais são pouco participativos. }\end{array}$ & $33,3 \%$ & $\begin{array}{l}\text { “... acho que a escola já faz a parte dele, promovendo } \\
\text { situaçóes que possibilitem o envolvimento, se ele náo ocorre } \\
\text { ai o problema está na própria família... pode ser falta de } \\
\text { interesse, de possibilidade e até mesmo de conhecimento....". }\end{array}$ \\
\hline Enviar tarefas para casa. & $31,4 \%$ & $\begin{array}{l}\text { "... penso que a melhor estratégia para envolver os pais em } \\
\text { casa seja o envio de tarefas para casa que exijam algum } \\
\text { tipo de auxilio dos pais, garantindo um envolvimento deste } \\
\text { durante sua realização...". }\end{array}$ \\
\hline $\begin{array}{l}\text { Troca de informaçóes/diálogos e } \\
\text { conversas. }\end{array}$ & $12,9 \%$ & $\begin{array}{l}\text { "... através de diálogos, troca de informaçōes sobre a crian- } \\
\text { ça e sua aprendizagem...". }\end{array}$ \\
\hline Reunióes. & $5,5 \%$ & $\begin{array}{l}\text { "...um meio do pai participar mais das coisas seria partici- } \\
\text { pando mais das reuniöes...". }\end{array}$ \\
\hline $\begin{array}{l}\text { Flexibilidade de horários para atender } \\
\text { os pais/reunióes. }\end{array}$ & $3,7 \%$ & $\begin{array}{l}\text { “... na minha opiniäo, um dos principais problemas é que } \\
\text { o horário de atendimento na escola é muito restrito, e as } \\
\text { reuniöes sempre säo em horário comercial, e os pais que tra- } \\
\text { balham não podem participar... Então, acho que a escola } \\
\text { tem que ser mais flexivel em relação aos horários para que } \\
\text { mais pais possam participar...". }\end{array}$ \\
\hline $\begin{array}{l}\text { Diferentes meios de contatar os pais } \\
\text { para melhorar a comunicação. }\end{array}$ & $1,8 \%$ & $\begin{array}{l}\text { “... como a maioria dos pais trabalham, eu acho que a } \\
\text { escola deve diversificar os meios de contato para ampliar } \\
\text { a comunicação com os pais...”. }\end{array}$ \\
\hline
\end{tabular}

Fonte própria

Os dados da Tabela 7 indicam que, segundo os professores, para atrair os pais à escola seria necessário: A escola ser mais atrativa, Orientar sobre como realizar o envolvimento e Enviar 
tarefa pra casa. Os professores responderam também, que $A$ escola já faz a parte dela, porém os pais sáo pouco participativos.

A Tabela 8 apresenta a opinião dos pais sobre o que a escola poderia fazer para aproximar os pais da escola.

Tabela 8 - Opiniâo dos pais sobre o que a escola deveria fazer para aproximar os pais da escola

\begin{tabular}{|c|c|c|}
\hline Categorias & $\%$ & Trechos Ilustrativos \\
\hline $\begin{array}{l}\text { Orientar os pais sobre como realizar o } \\
\text { envolvimento. }\end{array}$ & $28,3 \%$ & $\begin{array}{l}\text { "... a escola deveria realizar palestras e momentos em que } \\
\text { orientasse os pais a melhor maneira de participar da escola- } \\
\text { ridade dos seus filhos...". }\end{array}$ \\
\hline A escola já faz sua parte e é suficiente. & $25,0 \%$ & “... acho que a escola já faz o que é necessário...". \\
\hline O problema reside nos pais. & $21,6 \%$ & $\begin{array}{l}\text { “...eu acho que a escola promove muitas coisas para atrair os } \\
\text { pais, o problema é que muitos deles realmente não fazem a } \\
\text { minima questão de participar...". }\end{array}$ \\
\hline Trocar informações/diálogos/conversas. & $6,6 \%$ & $\begin{array}{l}\text { "Acho que a escola poderia proporcionar momentos de } \\
\text { conversas com os pais para que eles se sintam mais a } \\
\text { vontade...". }\end{array}$ \\
\hline Enviar tarefas para casa. & $20,0 \%$ & $\begin{array}{l}\text { “...eu entendo que a lição de casa é uma boa forma da } \\
\text { escola proporcionar o envolvimento...". }\end{array}$ \\
\hline $\begin{array}{l}\text { Escola ser mais atrativos aos pais/açóes } \\
\text { que tragam os pais. }\end{array}$ & $15,0 \%$ & $\begin{array}{l}\text { "Acho que a escola precisa escolher melhor a forma de } \\
\text { chamar os pais para a escola. Acho muito desagradável ser } \\
\text { chamada para só ouvir sobre o fracasso do meu filho, às } \\
\text { vezes nem tenho vontade de comparecer...". }\end{array}$ \\
\hline $\begin{array}{l}\text { Maior flexibilidade de horários da escola } \\
\text { para atender pais que trabalham. }\end{array}$ & $13,3 \%$ & $\begin{array}{l}\text { "... eu conheço muitos pais que gostariam de participar } \\
\text { mais, mas não conseguem porque trabalham... Eu acho que } \\
\text { a escola deveria ter horários mais flexiveis para atender todo } \\
\text { mundo". }\end{array}$ \\
\hline $\begin{array}{l}\text { Convocar os pais para realizar atividades } \\
\text { na escola. }\end{array}$ & $6,6 \%$ & $\begin{array}{l}\text { “...acho que os pais precisam ser convocados formalmente } \\
\text { para que participem...”. }\end{array}$ \\
\hline Reuniōes. & $5,0 \%$ & $\begin{array}{l}\text { "Convocando os pais para reuniōes de pais com maior } \\
\text { frequência...". }\end{array}$ \\
\hline
\end{tabular}

Fonte própria

Em relação à opinião dos pais sobre como a escola poderia ser mais atrativa, estes responderam: Orientando sobre como realizar o envolvimento, A escola já faz sua parte, e é suficiente, $O$ problema reside nos pais, Enviando tarefas para casa e $A$ escola ser mais atrativa. Estes resultados corroboram com as respostas dos professores sobre como a escola pode ser mais atrativa aos pais.

Como é possível identificar nos dados das Tabelas 7 e 8, professores e pais indicam que a escola precisa ser Mais atrativa para chamar os pais à escola. Alguns professores relataram que a abordagem da escola para tratar os pais de alunos com NEE nem sempre é adequada e convidativa. Este tipo de abordagem dificulta o contato com as famílias e promove o desinteresse dos pais. Segundo Oliveira e Marinho-Araújo (2010), o maior desafio dos profissionais da educação é justamente modificar a relação família-escola no sentido de que ela 
possa estar associada a situaçóes agradáveis e ter impacto positivo o processo de aprendizado e desenvolvimento dos alunos.

Outra resposta comum para professores e pais foi à necessidade da escola Orientar sobre como realizar o envolvimento. Segundo esses participantes, muitas vezes, os pais até têm vontade de participar, mas não sabem exatamente como sua ajuda pode ser válida. Esse dado ressalta a importância de se investir em ações que promovam o envolvimento parental para que este ocorra de maneira mais eficiente. Essa necessidade pode ser identificada na literatura brasileira, que apresenta diversos estudos ressaltando a importância de promover o envolvimento, principalmente quando se trata de alunos com NEE (BHERING; DE NEZ, 2002; CIA; D’AFFONSECA; BARHAM, 2004; SOARES; SOUZA; MARINHO, 2004).

Professores e pais também salientaram que percebem que a escola muitas vezes faz sua parte, porém os pais são pouco participativos, e ainda na resposta dos pais foi possível identificar que alguns destes percebem que o problema reside nos pais. Este dado chama a atenção ao fato de que muitas vezes os professores podem desenvolver visóes preconceituosas sobre a pouca participação dos pais, que considera o baixo envolvimento desinteresse (CAMPOS; FÜLLGRAF; WINGGERS, 2006). É importante salientar que não é possível generalizar e que muitas vezes esse baixo envolvimento se dê por razóes diversas, sendo necessário analisar caso a caso para entender a pouca participação e atuar de maneira a aumentar o envolvimento considerando a realidade de cada família.

O Envio de tarefas para casa também foi identificado pelos participantes como forma de promover a aproximação dos pais à vida escolar dos filhos. Uma das formas mais comuns de se realizar o envolvimento parental seria por meio do suporte parental à aprendizagem em casa, podendo ocorrer de várias maneiras, mas a principal delas seria o apoio à realizaçáo da tarefa de casa (BROWN; BECKET, 2007; EPSTEIN, 1995; SMITH, 1998). Diante disto, a indicação de tarefas pela escola para serem realizadas em casa, podem de fato ser importantes e promover o envolvimento dos pais à vida escolar dos filhos.

\section{Conclusóes}

Por meio desta pesquisa foi possível atingir os objetivos propostos de identificar e descrever a percepção de pais e professores sobre a relação família-escola no processo de inclusão. Os resultados indicaram que em relação aos aspectos das escolas que poderiam determinar o sucesso do aluno com NEE, segundo o professor seriam: apoio dos profissionais especializados assessorando professores da sala comum, o respeito à diversidade, a realização de adaptaçóes ao espaço físico e aos materiais didáticos, e a troca de informaçóes com a família. Esses aspectos apontados pelo professor expressam a preocupação em oferecer oportunidades e condiçóes iguais e aquadas aos alunos com NEE, e estão em consonância com as políticas inclusivas atualmente em vigor em nosso país.

No que diz respeito à opinião dos pais sobre como sua colaboração com a escola pode ser importante ao sucesso de seu filho, os mesmos apresentaram uma grande diversidade de respostas, indicando possivelmente pouca clareza destes, sobre como seu auxílio pode ter influências no desempenho da criança. Em relação ao que consideravam uma boa relação família-escola, tanto professores como pais consideraram a comunicação e uma maior 
participação dos pais na escola, como características mais importantes de uma boa relação família-escola. Este resultado indica que provavelmente o tipo de concepção que os pais têm sobre a relação família-escola é muito restrita, limitando sua ação dentro da escola.

Os professores demonstraram entender que sua ajuda pode ser importante aos pais para transmitir informaçóes sobre o desenvolvimento da criança, incentivando a aprendizagem e sobre como realizar o envolvimento. Os pais concordaram com os professores dizendo que podem ser úteis a estes, transmitindo informaçóes sobre o desenvolvimento da criança e incentivando a aprendizagem. Pais e professores concordaram ao dizer que entendem ser necessário que a escola seja mais atrativa para promover a participação dos pais na escola. Alguns professores indicaram que entendem que a abordagem da escola para tratar os pais de alunos com NEE nem sempre é adequada e convidativa. Além disso, indicaram a necessidade de orientar sobre como realizar o envolvimento, embora os pais até tenham vontade de participar enfrentavam muitas dificuldades e dúvidas de como podem ser úteis, ressaltando a necessidade de promover açóes em prol da relação.

Esses dados indicam que em relação ao processo de inclusão, os professores apresentaram uma percepção bastante diversificada do que seria importante ao sucesso do aluno com NEE. No que diz respeito à relação família-escola, é possível identificar que embora pais e professores reconhecam a importância de uma relação mais próxima, ainda existem lacunas na relação, que colocam em dúvida qual seria a melhor forma de agir, principalmente no que diz respeito ao papel dos pais. Por outro lado, os dados indicaram que os professores precisavam também repensar aspectos da relação estabelecida, compreendendo características individuais de cada família e da criança com NEE, para efetivar uma relação possível e positiva entre as duas instâncias.

Conforme afirma Pereira (1996), uma relação parental próxima à escola é positiva a todos os envolvidos, mais do que os alunos, as famílias também são beneficiadas pelas seguintes razões: possibilidade de conhecer seus direitos e responsabilidades; conhecer informaçóes sobre a deficiência do filho, recebendo informaçóes específicas sobre como a criança se desenvolve e sobre como poderá ajudar nesse processo; conhecer os tipos de atividade que pode realizar em casa; aprender como ensinar novas competências as crianças; e, conhecer outros recursos que possam ajudar no desenvolvimento da criança. Consequentemente, a escola, também seria benificiada, na medida em que os pais pudessem se envolver de maneira mais adequada na escolaridade como açóes mais efetivas. Neste sentido, açóes que implementam a comunicação entre as duas instâncias são necessárias, promovendo uma comunicação eficiente e contínua de modo a contribuir de maneira ininterrupta com o desenvolvimento tanto em casa, como na escola.

Segundo Bronfenbrenner (2011), uma comunicação efetiva deve ser estabelecida entre as instâncias, de modo que possam compreender as particularidades, tanto das famílias, quanto do que ocorre na escola. Havendo uma compreensão empática entre as duas partes, maior a possibilidade de contribuição e de diálogo entre as duas e colaboração entre os microssistemas, trazendo benefícios para todos os envolvidos, promovendo o desenvolvimento do aluno e dos processos que ocorrem em cada microssistema, permitindo a ocorrência de aprendizado entre ambos. 
Espera-se assim, que esses dados possam ser empregados positivamente, podendo ser considerados como parte de criação de um plano de ação para as escolas participantes, de modo a promover a relação família-escola e o processo de inclusão dos alunos pré-escolares na rede municipal de educaçáo, garantindo não apenas o acesso como também todos os serviços necessários para promover, não só a permanência, mas o aproveitamento pleno do aluno com NEE.

\section{REFERÊNCIAS}

ALMEIDA, L. M. A. C.; CHRISTOVAM, A. C. C. Um estudo sobre a percepção de mães e professores sobre a importância da tarefa de casa. Relatório de pesquisa. UNIMEP: Piracicaba. Náo Publicado. 2008.

BEE, H. A criança em desenvolvimento. Porto Alegre: Artmed, 1996.

BHERING, E.; SIRAJ-BLATCHFORD, I. A relação escola-pais: um modelo de trocas e colaboração. Cadernos de Pesquisa, São Paulo, v.106, n.1, p.191-216. 1999.

BHERING, E.; DE NEZ, T. B. Envolvimento de pais em creches: possibilidades e dificuldades de parceria. Psicologia: Teoria e Pesquisa, São Paulo, v.18, n.1, p.63-73, 2002.

BORGES,L.; GUALDA, D. S.; CIA, F. O papel do professor na relação com as famílias de crianças pré escolares incluídas. In: CONGRESSO BRASILEIRO MULTIDISCIPLINAR DE EDUCAÇÃO ESPECIAL, 6.; ENCONTRO DA ASSOCIAÇÃO BRASILEIRA DE PESQUISADORES EM EDUCAÇÃO ESPECIAL, 7., 2011. Anais... Londrina. p.1249-1256. 2011.

BRASIL. Senado Federal. Lei de Diretrizes e Bases da Educação Nacional: no 4024/61. Brasília: 1961.

BRASIL. Senado Federal. Lei de Diretrizes e Bases da Educação Nacional. Brasília: 1996.

BRASIL. Ministério da Educação. Educação Infantil - Saberes e Práticas da inclusão: Introdução. Brasília: 2006.

BRASIL. Ministério da Educação. Secretaria de Educação Especial. Política Nacional de Educação Especial na Perspectiva da Educação Inclusiva. Brasília: 2008.

BRAZELTON, T.B; GREENSPAN, S.I. As necessidades especiais das crianças. Porto Alegre: ARTMED. 2002.

BRONFENBRENNER, U. A ecologia do desenvolvimento humano: Experimentos naturais e planejados. Ed 1. Porto Alegre: Artes Médicas, 1996.

BRONFENBRENNER, U. Bioecologia do desenvolvimento humano: tornando os seres humanos mais humanos. São Paulo: Artemed, 2011.

BROWN, L. H.; BECKETT, K. S. Parent involvement in alternative school for students at risk of educational failure. Education e Urban Society, Vancouver, v.39, p.498-523, 2007.

CAMPOS, M.M.; FÜLLGRAF, J.; WINGGERS, V. A qualidade da educação infantil brasileira: alguns resultados da pesquisa. Cadernos de Pesquisa, São Paulo, v.36, n.127, p.87-128, 2006.

CAPELLINI V.M. F; MENDES, E. O ensino colaborativo favorecendo o desenvolvimento profissional para a inclusão escolar. Educere et Educare Revista de Educação, São Paulo, v.2, n.4, p.113$128,2007$.

CIA, F; D’AFFONSECA, S.M.; BARHAM, E.J. A relação entre o envolvimento paterno e desempenho o acadêmico dos filhos. Paideia, Ribeirão Preto, v.14, n.29, p.277-286, 2004. 
CIA, F.; PAMPLIN, R.C.O.; DEL PRETTE, Z.A.P. Comunicação e participação pais-filhos: Correlação com habilidades sociais e problemas de comportamento dos filhos. Paidéia, Ribeirão Preto, v.6, n.35, p.395-406, 2006.

CIA, F.; PAMPLIN, R.C.O.; WILLIAMS, L.C.A. O impacto do envolvimento parental no desempenho acadêmico de crianças escolares. Psicologia em Estudo, Maringá, v.13, n.2, p.351-360, 2008.

COZBY, P.C. Métodos de pesquisa em ciências do comportamento. ed. 2. São Paulo: Editora Atlas, 2006.

DIAS, J.C. A problemática da relação família/escola e a criança com necessidades educativas especiais. Coleção Cadernos SNR no. 11. Portugal: Instituto Jean Piaget, 1996.

DUARTE, M.I. Formação de adultos e cidadania: (Re)pensar as práticas de envolvimento parental na escola. 2001. Dissertação de Mestrado em Ciências de Educação. Universidade nova de Lisboa, Faro, 2001.

DURLAK, J.A. Successful prevent programs for children and adolescents. New York: Plenum Press, 1997. EPSTEIN, J. L. School/family/community partnerships: Caring for the children we share. Phi Delta Kappan, Bloomington, v.76, n.9, p.701-712. 1995.

FERREIRA, S.L.G.; TRICHES, M.A. O envolvimento parental nas instituiçóes de educação infantil. Revista Pedagógica, Chapecó, v.11, n.22, 2009.

GROLNICK, W.S.; SLOWIACZEK, M.L. Parents' involvement in children’s schooling: A multidimensional conceptualization and motivational model. Child Development, Worcester, v. 65, p.237-252, 1994.

MARCHESI, A. Desenvolvimento e educação de crianças surdas. In: COLL, C.; MARCHESI, A.; PALÁCIOS, J. (Org.). Desenvolvimento psicológico e educação: Transtornos do desenvolvimento e necessidades educativas especiais. Porto Alegre: Artmed. 2004. p.171-192.

MAZZOTTA, M.J.S. História da educação especial no Brasil. In: MAZZOTTA, M.J.S. (Org.). Educação especial no Brasil - História e políticas públicas. São Paulo: Cortez. 1996. p.37-49.

MENDES E. G. A radicalização do debate sobre inclusão escolar no Brasil. Revista Brasileira de Educação, Rio de Janeiro, v. 11, n. 33, p. 387-405, 2006.

OLIVEIRA, C.B.E.; MARINHO-ARAÚJO, C.M. A relação família-escola: intersecçôes e desafios. Estudos de Psicologia, Campinas, v.27, n.1, p.99-108, 2010.

PAMPLIN, R. A interface família-escola na inclusão da criança com necessidades educacionais especiais. 2005. 117f. Dissertação (Mestrado em Educação Especial) - Programa de Pós-graduação em Educação Especial, Universidade Federal de São Carlos, São Carlos. 2005.

PANIAGUA, P.; PALACIOS, J. Educação Infantil - resposta educativa à diversidade. ed. 1. Porto Alegre: Artmed, 2007.

PANG, Y. H. Factors associated with the experiences of parents in the transitioning of their young children from early intervention to programs for three-year-olds. Dissertation Abstract International, Ann Arbor, v.69, n.3, p.870, 2008.

PEREIRA, F. As representaçôes dos professores de educação especial e as necessidades das familias. 1996. 127f. Tese (Doutorado em Educação) - Secretariado Nacional para reabilitação e integração das pessoas com deficiência, Lisboa, Portugal. 1996 
POLONIA, A.C.; DESSEN, M.A. Em busca de uma compreensão das relaçóes entre família e escola. Psicologia Escolar e Educacional, Campinas, v.9, n.2, p.303-312, 2005.

SAMPIERI, R.H.; COLLADO, C.H.; LUCIO, P.B. Metodologia de pesquisa. ed. 3. São Paulo: McGraw-Hill, 2006. p.583.

SIGOLO, S.R.R.L. Educação de Crianças com Atraso no desenvolvimento na perspectiva de Bronfrenbrenner. In: SIGOLO, S.R.R.L; MANZOLI, L.P. (Org.). Educação especial face ao desenvolvimento e a inserçâo social. Araraquara: Cultura Acadêmica Editora, 2002. p.11-39.

SMITH, B. Effects Of Home-School Collaboration And Different Forms Of Parent Involvement On Reading Achievement. 1998. 125f. Tese (Doutorado em educação) - Faculty of the Virginia Polytechnic Institute and State University. Varginia. Richmond.1998.

SOARES, M. R. Z.; SOUZA, S. R.; MARINHO, M. L. Envolvimento dos pais: incentivo à habilidade de estudo em crianças. Estudos de Psicologia, Campinas, v.21, n.3, p.253-260, 2004.

VALLE, L.E.L.R. Psicologia e prevenção na educação infantil. In: CAPOVILLA, F.C. (Org.). Neuropsicologia e aprendizagem: uma abordagem multidisciplinar. São Paulo: Memnon, Capes e Sociedade Brasileira de Neuropsicologia. 2002. p.320-370

VILAS BOAS, M.A. A parceria entre a escola, a familia e a comunidade: estratégias de envolvimento parental. Lisboa: Ministério da Educação, Departamento da Avaliação Prospectiva e Planejamento, PRODEP, 2001.

XU, Y;; FILLER, J. Facilitating family involvement and support for inclusive education. School Community Journal, Lincoln, v.18, n.2, p.53-72, 2008.

ZENHAS, A.M. Direcção de turma no centro da colaboração entre a escola e a família. 2004. 212f. Dissertação (Mestrado em Formação Psicológica de Professores) - Universidade do Minho. Minho, Portugal. 2004.

Recebido em: 07/02/2013

Reformulado em: 09/09/2013

Aprovado em: 21/09/2013 